\title{
La estrecha ruta hacia la globalización de la solidaridad
}

\author{
Francisco Javier Ibisate S. J.* \\ Universidad Centroamericana "José Simeón Cañas" \\ El Salvador
}

\section{Resumen}

En este artículo, el autor explica el surgimiento - comentado por Frank Hinkelammert- de un movimiento de recuperación de la globalidad de la humanidad y la tierra, contra la estrategia de acumulación de capital, que ha asumido, de forma ilegítima, el nombre de globalización, que en lugar de globalizar el mundo, lo destruye globalmente. Cada vez más es voz común y persuasión, incluso entre las elites mundiales, que el proceso no está cerrado; más aún, que el proceso de la globalización no está predeterminado ni económica ni social ni políticamente, y que, por tanto, puede ser dirigido hacia niveles de mayor humanidad, más equidad y más justicia social. En tal sentido, los "modelos" económicos están hechos para "remodelarse" de acuerdo al giro de la historia y a partir de la experiencia. Así, todo "experimento" debe ser evaluado porque puede ser que no se haya escogido el modelo más adecuado para el momento histórico del país y porque también suele ocurrir que las fuerzas o los grupos, internos y externos, de poder desvíen dicho modelo de los objetivos pactados, ya que cada grupo social los lee desde su propio interés. Es peor aún cuando el modelo se impone para defender determinados intereses minoritarios con el en-

* Catedrático del Departamento de Economía de la UCA. 
voltorio de democracia, libertad, progreso humano, justicia y paz social, lo cual parece ser el caso de la globalización neoliberal, cuyo experimento histórico pretende evaluar el autor desde algunas cumbres mundiales internas y externas al modelo.

\section{El final principio}

A las puertas del tercer milenio "el fin de la historia”, como única alternativa económica, entra en crisis interna y se ve sometido a crecientes críticas externas, porque la autodenominada globalización es más lo que excluye que lo que incluye. Sus dos largas décadas de dominio mundial parecen actualizar la obra de Paul Kennedy, El auge y la caida de los grandes imperios. La crisis interna de la globalización no significa que sus inspiradores entren en un proceso de autocrítica, porque el dogma económico no la permite. La autocrítica sería una herejía: el error no está en el modelo, sino en su mala aplicación. "La culpa la tienen siempre quienes aplican el modelo, porque lo aplican mal", comenta Luis de Sebastián. "Pero si nadie nunca es capaz de aplicar el modelo neoliberal bien, ¿no será que el modelo es inaplicable?; ¿no será que el modelo y las políticas que prescribe son nefastas para el mundo real, que es el único que existe? $\mathrm{Si}$ los políticos y las realidades políticas de los países emergentes son los responsables de que los modelos y las medidas económicas que de ellos se derivan no funcionen bien, será misión de quienes diseñan los modelos tener en cuenta estas realidades, que son bien conocidas y analizables. El mundo está lleno de imperfecciones y rozamientos que hacen que los modelos teóricos no se puedan aplicar en forma pura nunca a ninguna realidad". Por ello, al no tomar en cuenta la realidad, los sucesivos gobiernos nos ofrecen más de lo mismo. No hay espacio para terceras vías.

Al mismo tiempo, "el malestar en la globalización" hace crecer el número de los inconformes, siempre presentes en las grandes cumbres mundiales, y que, llegado el nuevo milenio, transforman sus protestas en propuestas alternativas, con el lema: "otro mundo es posible". A partir de 2001, se van a enfrentar, en las mismas fechas, "el hombre de Davos" y "el hombre de Porto Alegre", congregados en dos foros mundiales, económico uno y social el otro. No será éste el único foco de protestas y pro- puestas, que también surgen del interior del primer mundo, de reconocidos académicos e intelectuales, incluso desde las agendas del foro de Davos. En forma breve, recordamos algunas de las propuestas alternativas. Es un botón de muestra del final al principio.

Frank Hinkelammert, luego de comentar que las "burocracias privadas", grandes transnacionales, se han convertido en un gobierno extraparlamentario, que socava los derechos humanos, anuncia el resurgimiento de la esperanza. "Pero no todo es desesperanza. Aparecen cada vez más movimientos contestatarios. Estos movimientos vienen en nombre de la idea de que un mundo mejor es posible. Se coordinan entre sí, sin intentar formar un gran movimiento unificado. Estos movimientos tampoco forman partidos políticos, aunque varios partidos los apoyan. Llegan a ser conocidos con grandes manifestaciones en ocasión de las reuniones de los organismos financieros internacionales. Se hacen presentes en los últimos años, en Seattle, Davos, Praga, Génova y Quebec. En 2001 se reúnen la primera vez a escala mundial en la ciudad brasileña de Porto Alegre, donde organizan un congreso de decenas de participantes. Un congreso parecido se reunió a fines de enero de 2002 en el mismo lugar, donde esta vez hubo más de 50,000 participantes de todo el mundo. Estos movimientos promueven un pensamiento en términos de alternativas, con una doble orientación: por un lado, para obligar al sistema mundial a reformular toda su estrategia de acumulación de capital, llamada estrategia de globalización, y, por el otro, responder a la desesperanza que cada vez más desemboca en reacciones irracionales sin destino" ("El socavamiento de los derechos humanos en la globalización actual: la crisis del poder de las burocracias privadas", Realidad 2002, 87, pp. 328-329).

Se trata, pues, de un movimiento cuyos participantes provienen de todos los sectores de la población. En sentido literal, no es un movimiento contrario a la globalización, sino un movimiento que 
enfrenta a la acumulación mundial actual del capital. Lo hace, precisamente, porque hoy el mundo es global y es necesario defenderlo ante esta estrategia - autoproclamada globalización-. Esta estrategia se ha convertido en la peor amenaza para la sostenibilidad de la humanidad y de la tierra. Es un movimiento de la tierra hecha global por los "globalizadores", provenientes de las burocracias privadas $\mathrm{y}$ apoyados por gobiernos que se sienten responsables ante el capital, en vez de ser responsables frente a la gente y el mundo. La globalización resulta ser más bien un "pillaje" global de toda la tierra.

Frente a este pillaje global surge un

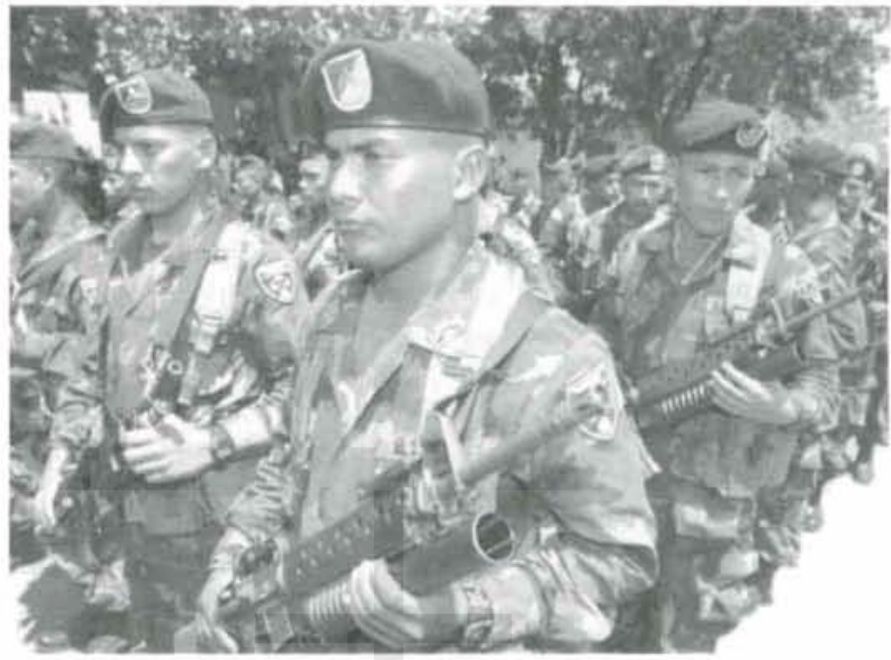
movimiento de recuperación de la globalidad de la humanidad y la tierra, en contra de la estrategia de acumulación de capital, que ha asumido, de forma ilegítima, el nombre de globalización. En vez de globalizar el mundo, lo destruye globalmente. Este movimiento está en auge y ha adquirido una gran legitimidad, en la opinión mundial, e incluso en muchos representantes de las clases altas. Está presente en todos los países y en todos los sectores de la población. Está haciendo conciencia de las consecuencias fatales que la actual estrategia tiene para el futuro de la humanidad. Se está transformando en el núcleo de una conciencia alternativa: un mejor mundo es posible. Hace ver que la misma globalidad de la tierra exige una alternativa. Mientras, a escala mundial, en muchos, la desesperanza lleva a la desesperación con sus consecuencias irracionales y sin sentido, aparece una gran recuperación de la esperanza, que también mundialmente se hace notar y que muestra una salida.

Con un título parecido al lema de Porto Alegre, Luis de Sebastián publicó su obra Un mundo por hacer: claves para comprender la globalización (Madrid, 2002). Unos párrafos de su introducción nos sirven como segundo botón de muestra de esa marcha hacia una globalización más humana. "El mundo está por hacer. La historia no ha terminado. La humanidad tiene todavía enormes tareas pendientes. El tipo de vida que conocemos y que es posible para unos pocos cientos de millones de personas es todavía un sueño imposible para otros miles de millones. Pero la humanidad tiene recursos y conocimientos para que todos los seres humanos

lleven una vida larga, pacífica, llena de sentido, rica en contenido y provechosa. $\mathrm{Si}$ todos los seres humanos no consiguen tenerla es únicamente porque hemos organizado mal la distribución de los medios necesarios para la vida. Esta mala organización del mundo es un estímulo para seguir trabajando. Es una prueba de que hay todavía mucho por hacer. Hay que alimentar a millones de personas. Hay que curar a millones de enfermos que mueren de enfermedades, los remedios para las cuales conocemos y fabricamos. Tenemos que terminar con las decenas de guerras civiles, fratricidas y en todo caso insensatas, que causan miles de muertes y millones de refugiados. Debemos acabar con el terror que se causa a los pueblos asesinando a terceros inocentes, con la esclavitud que ha adoptado nuevas formas y terribles proporciones, con el tráfico de drogas que causan efectos nefastos entre la juventud. No sé cómo a alguien, que tiene los ojos abiertos a lo que pasa en el mundo, se le puede ocurrir la idea de que ya podemos descansar, porque una vez derrotado el comunismo, ya no quedan tareas importantes para la humanidad" (pp. 9-10).

Afortunadamente, cada vez penetra más en la conciencia de las sociedades ricas el convencimiento de que el mundo está todavía por hacer. Se van persuadiendo de que lo conseguido hasta ahora, por medio de los procesos de innovaciones y cambios a escala mundial, que llamamos frívolamente globalización o mundialización, no es bastante para cantar victoria. Cada vez más es voz común y persuasión incluso entre las elites mundiales que el proceso no está cerrado, más aún, que el proceso 
de la globalización no está predeterminado ni económica ni social ni políticamente, y que, por tanto, puede ser dirigido hacia niveles de mayor humanidad, más equidad y más justicia social. De hecho se dan avances, pequeños quizás, pero significativos, en muchos campos, que hace poco tiempo parecían cerrados a la compasión y la racionalidad humanas. Por ejemplo, el problema de la deuda externa de los países más pobres del mundo, que hoy todos los gobiernos de las naciones ricas y los organismos internacionales reconocen que se debe resolver pronto para que estos países tengan algún grado de viabilidad económica y política. $\mathrm{O}$ la nueva ronda de negociaciones comerciales acordada en Doha (Qatar, 2001), donde los países en vías de desarrollo van a poder poner sobre la mesa de negociaciones sus quejas, sus problemas y sus pretensiones. Estos pequeños avances transmiten al mundo el mensaje de que el proceso está abierto, de que son posibles cambios insospechados, si se saben formular, argumentar e impulsar. Y sobre todo transmiten a los países más pobres un mensaje de esperanza, la esperanza de que su suerte puede cambiar a mejor.

Lastimosamente, Luis de Sebastián no podía conocer entonces que la cumbre de Doha terminaría con una serie de promesas relacionadas con la "reducción progresiva de todas las subvenciones y subsidios agrícolas", la concesión limitada de la producción de medicamentos genéricos y de pocas cosas más. Dos años después, Estados Unidos y la Unión Europea no habían cumplido sus promesas. Por eso, la cumbre de Cancún de la Organización Mundial del Comercio volvió a ser un fiasco similar a la de Seattle. Más adelante, Luis de Sebastián comenta "las protestas contra la globalización, la visibilidad del poder, la protesta tiene que ser sin violencia". La globalización - explica de Sebastián - genera también un nuevo estilo de protesta. Las nuevas protestas contra los nuevos costos y las nuevas víctimas del proceso de globalización se diferencian porque se dirigen contra un poder difuso, lejano, inalcanzable, que ni dialoga ni negocia con el hombre de la calle, al que solo se puede acceder indirectamente, aprovechando las ocasiones cuando este poder se hace visible, como en las reuniones de empresarios en Davos o durante las reuniones periódicas del Banco Mundial, del Fondo Monetario Internacional, la OTAN u otros organismos internacionales. Estas circunstancias hacen del movimiento de protesta un movimiento abigarrado y algo caótico, porque las ecuaciones y las demandas son muy variadas, no siempre bien articuladas y no siempre compatibles unas con otras. No obstante, el movimiento es un hecho de gran trascendencia histórica, que no se puede ignorar, y el impulso que lo pone en movimiento es tan real como la vida misma. La libre expansión del motivo de lucro a todas las esferas de la vida humana ha creado enormes injusticias, discriminaciones, abandonos y abusos. Hay que reconocerlo para no permitir que el individualismo nos lleve a la ruina y el caos. No todos los integrantes del movimiento antiglobalización tienen razón, pero el conjunto sí la tiene. Y hay que dársela, de palabra y de obra, abriéndose a sus propuestas más realistas y razonables y tratando de realizarlas. La alternativa no es mayor prosperidad, sino una nueva clase de tensiones y problemas mundiales (pp. 27-28).

A medida que avanza la década de los noventa, al mismo tiempo que crece la crítica a la economía neoliberal, crece también la nostalgia de regímenes económicos sociales que desean readecuarse al nuevo marco de la economía mundial como alternativa a la globalización imperante. Esta crítica constructiva viene desde "el río arriba", puesto que el siglo XX ha sido no solo el de la confrontación esteoeste, sino que también ha sido "la historia de los hermanos irreconciliables socialistas". No existen "modelos" económicos prefabricados; hay que construirlos. Los fundadores de la economía social de mercado, L. Erhard, K. Adenauer, A. Muller-Armarck, "extrajeron importantes conclusiones de las terribles experiencias de la crisis económica mundial y del abuso desenfrenado del poder en que habían incurrido las dictaduras", tanto la del nacional socialismo nazi como la del comunismo soviético en Alemania del este.

En el resto de Europa occidental, se gestó el Estado social de bienestar, inspirado en principios sociales o social democráticos, cuyos dirigentes accedieron al poder por la vía parlamentaria. Esta corriente se opone al libre juego del mercado y a la dictadura de un partido todopoderoso. Durante tres largas décadas, ambos modelos lograron las mayores tasas de crecimiento, junto con una adecuada distribución equitativa de las rentas y de la seguridad social. La democracia, la equidad social, el bien común y la solidaridad eran ejes centrales de estos dos regímenes económicos. Al igual que el resto de las economías del este y del oeste, ambos regímenes entraron en el proceso de estanflación económica mundial, luego de 1973, al mismo tiempo que re- 
vivía la nostalgia del pasado. "El nivel de bienestar material alcanzado por las economías más avanzadas ha sido resultado de este mayor reparto de los beneficios del crecimiento. El cuestionar el Estado de bienestar resulta, por tanto, regresivo en relación con la igualdad económica y social y los derechos de ciudadanía, lo cual no quiere decir que no haya que proceder a reformas necesarias y en consonancia con los tiempos actuales, si se pretende asegurar la viabilidad del Estado de bienestar" (Berzosa et alii, Estructura económica mundial, Madrid, 2001, p. 139).

Desde la nostalgia realista del pasado proliferan numerosos encuentros de crítica constructiva al neoliberalismo, las cuales se presentan como propuestas alternativas al "fin de la historia". En 1993, en Santafé de Bogota, tuvo lugar un seminario sobre "Ética, economía, política y pobreza: el desafío crucial para latinoamérica", organizado por el CELAM y CIEDLA y la Konrad Adenauer Stiftung. Los ponentes se centraron en la economía social de mercado y la doctrina social de la Iglesia. La introducción hace referencia a la cumbre sobre el desarrollo social de Copenhague (1995), que "nos muestra que el desarrollo con justicia social debe ser un compromiso de toda la comunidad internacional y de cada persona, porque cada uno de nosotros está llamado a cooperar en la construcción de un mundo más humano y fraterno".

En las mismas fechas tuvo lugar, en Barcelona, un seminario, "El neoliberalismo en cuestión", organizado por Cristianisme i Justicia. La introducción de Luis de Sebastián es ilustrativa, "El neoliberalismo: argumentos a favor y en contra". Aquí, la nostalgia gira más bien en torno al Estado social de bienestar, la cual reapareció dos años más tarde en otro seminario, esta vez en Córdoba (España), "Los derechos económicos y sociales y el Estado de bienestar". En 1996, en México se publicó el documento "El neoliberalismo en América Latina", firmado por los dieciocho provinciales latinoamericanos de la Compañía de Jesús (Realidad 54, 1996, pp. 747-763). Su pensamiento gira en torno al Estado social de bienestar y a la enseñanza social de la Iglesia.

En 1999, aparecí La tercera vía: la renovación de la socialdemocracia, de Anthony Giddens, la cual coincide con la subida del poder de algunos gobiemos laboristas, socialdemócratas y socialistas, en Europa occidental. En noviembre de ese año, en Florencia, se reunieron algunos presiden- tes y jefes de gobiemo para discutir cómo injertar esos objetivos en el escenario de la globalización. Cada uno de estos líderes hizo su propia lectura de la tercera vía y de las dificultades de su respectivo país. No todos leyeron los objetivos de la tercera vía de la misma manera.

Los "modelos" económicos están hechos para "remodelarse" de acuerdo al giro de la historia y a partir de la experiencia. Todo "experimento" debe ser evaluado por dos motivos: pueda que no se haya escogido el modelo más adecuado para el momento histórico del país y también suele ocurrir que las fuerzas o los grupos, internos y externos, de poder desvíen el modelo de los objetivos pactados, porque cada grupo social los lee desde su propio interés. Peor aún, si el modelo se impone para defender determinados intereses minoritarios con el envoltorio de democracia, libertad, progreso humano, justicia y paz social. Este parece ser el caso de la globalización neoliberal, cuyo experimento histórico queremos evaluar desde algunas cumbres mundiales internas y externas al modelo. Es ahí donde surgen las protestas, a veces acompañadas de asomos de autocrítica, que derivan en propuestas alternativas al iniciarse el nuevo milenio.

\section{Evaluación del experimento neoliberal}

Este recorrido, breve por razones de espacio, de las cumbres mundiales de Naciones Unidas plantea un desafío a la globalización de la solidaridad. En 1992, la cumbre de "la tierra" o del deterioro ecológico (Río Janeiro) aprobó la "agenda 21", la cual fue olvidada hasta la siguiente cumbre (Johanesburgo, 2002). El modo de producción y consumo de las economías industrializadas amenaza el exterminio de los recursos naturales, la salud y la vida de millones de seres humanos. "Más de mil millones de personas no disponen de agua potable y casi tres mil millones consumen agua contaminada. Debido a la ingestión de esta agua 30000 personas mueren cada día. Son diez veces más, cada día, que el número de víctimas de los odiosos atentados del 11 septiembre" (Entorno económico mundial, UCA Editores, 2003, p. 252). El gobierno más contaminante del mundo se niega a firmar el protocolo de Kioto. En 1993, tuvo lugar la cumbre de los derechos humanos (Viena), sobre los cuales vuelve a insistir "La declaración del milenio" (2000). En 1994, la cumbre del crecimiento demográfico (El Cairo) aflige más a los países en desarrollo. En 1996, en la cumbre de la mujer (Beijing), el pro- 
blema aparece como una de las lacras sociales y vuelve en el foro social de Bombay (2004).

Los documentos de Naciones Unidas, previos a la cumbre del desarrollo social de Copenhague (1995), "Las sociedades prósperas son las que existen en función del ser humano", contrastan la realidad de la globalización con el logo "la pobreza se ha generalizado; disminuye el empleo productivo y crece la insolidaridad social; las sociedades se atomizan". Las estadísticas son lacerantes y Boutros Ghali habla de "darwinismo social". El creciente desempleo genera una crisis económica, social, mo$\mathrm{ral}$, de incertidumbre y de gobernabilidad. Al desempleo se suma el crecimiento de la población, la pobreza, la deuda externa y la degradación ambiental. La cumbre llegó, pasó y pocos celebraron su aniversario. "Cómo erradicar la pobreza de la humanidad. La contradicción principal de la cumbre radica en que, por un lado, dice que quiere erradicar la pobreza, pero por el otro lado, no puede desembarazarse del esquema neoliberal". No es extraño que los representantes de unas 2500 organizaciones no gubernamentales, reunidas en cumbre paralela, hayan declarado que la reunión oficial estaba llena de "palabras huecas" (ibíd., pp. 84-91).

En esas estábamos cuando, en 1997-1998, estalló la crisis mundial de los capitales especulativos financieros. La crisis surgió en los "tigres asiáticos" y sacudió las bolsas de valores desde Tokio a Wall Street y tambaleó economías tan distintas y distantes como Rusia y Brasil, ésta última, fiel discípula del Fondo Monetario Internacional. Estos capitales especulativos debilitan, con efecto dominó, las economías más pobres, que carecen de sistemas monetarios sólidos. El financiero y filántropo George Soros, experto de primera fila, ha dicho, "Aunque he hecho una fortuna en los mercados financieros, temo ahora que la intensificación sin trabas del capitalismo de laissez faire y la difusión de los valores de mercado en todas las áreas de la vida está poniendo en peligro nuestra sociedad abierta y democrática. La persecución sin inhibiciones del interés propio produce desigualdades e inestabilidad intolerables".

En efecto, los mercados financieros son inestables por naturaleza y más todavía los mercados financieros internacionales. Los participantes en ellos, si son racionales, advierte Soros, reconocerán que, "más que descontando un futuro equilibrio, están disparando contra un blanco en movimiento". Sin embargo, la idea de que los mercados deberían abandonarse a sus propios mecanismos, sigue siendo influyente. A Soros, esa idea le parece peligrosa, porque la inestabilidad de los mercados financieros puede originar dislocaciones económicas y sociales serias. Pero la inestabilidad no se reduce al mercado financiero. La meta de los competidores es predominar, no mantener la competencia en el mercado. La tendencia natural de los monopolios y oligopolios debe ser limitada con regulaciones “¿A quién corresponde evitar una concentración de poder indebido y salvaguardar la estabilidad? Esto me lleva al papel del Estado. Desde el final de la segunda guerra mundial, el Estado ha desempeñado un papel creciente en el mantenimiento de la estabilidad económica, y se ha esforzado por garantizar la igualdad de oportunidades y proporcionar una red de seguridad social, especialmente en las naciones altamente industrializadas de Europa y América del Norte" (ibíd., pp. 132-134).

Los gobiernos de Thatcher y Reagan comenzaron a reducir el papel del Estado en la economía. En consecuencia, los impuestos sobre el capital descendieron de forma significativa, mientras que los impuestos sobre el trabajo han seguido creciendo. Dani Rodrik, economista internacional, asegura que la globalización aumenta la demanda al Estado para que proporcione seguridad social, al tiempo que reduce su capacidad para ello. Aquí se encuentra el germen de los conflictos sociales. Esto lleva a un problema más confuso: el de los valores y la cohesión social. Toda sociedad necesita tener valores compartidos. Los valores del mercado no sirven para este propósito, porque solo reflejan lo que un participante está dispuesto a pagar a otro, en un intercambio libre. Los mercados reducen todo, incluidos los seres humanos y la naturaleza, a mercancía. Puede haber una economía de mercado, pero no una sociedad de mercado. Además de los mercados, la sociedad necesita instituciones con fines sociales como la libertad política y la justicia social. Esas instituciones existen en algunos países, pero no en la sociedad global. A menos que se acabe con esta diferencia, el capitalismo global no sobrevivirá (ibíd.).

En ciertos momentos, la crítica sale desde los centros del capitalismo. Cuando los miembros del G-7 (Washington, 1998) no hallan una solución a la crisis financiera mundial, J. Wolfensohn, presidente del Banco Mundial, pronuncia el discurso "La otra crisis". "Hoy mis recuerdos son muy distintos. Imágenes sombrías, sobrecogedoras de desesperación, 
impotencia y miseria. De personas que tuvieron esperanzas, pero las han perdido... Hoy, mientras hablamos de crisis financiera, 17 millones de indonesios han recaído en la pobreza... y 40 por ciento de la población rusa vive en pobreza. Hoy, mientras hablamos de crisis financiera, en todo el mundo, 1300 millones de personas subsisten con menos de un dólar al día; 3000 millones viven con menos de dos dólares al día; 1300 millones no tienen agua potable, 3000 millones carecen de servicios de saneamiento y 2000 millones no tienen electricidad" (ibíd., pp. 143-146).

En consecuencia, el presidente del Banco Mundial propuso ir más allá de la estabilización financiera y ocuparse de los problemas sociales. "Hemos comprobado que cuando pedimos a los gobiernos que adopten medidas rigurosas para organizar sus economías, podemos generar enormes tensiones. Quien sufre es la gente, no los gobiemos. Debemos aprender a entablar un debate en que las matemáticas no valgan más que las razones humanitarias, en que la necesidad de cambios, con frecuencia drásticos, sea compatible con la protección de los intereses de los pobres... No

El creciente desempleo genera una crisis económica, social, moral, de incertidumbre y de gobernabilidad. Al desempleo se suma el crecimiento de la población, la pobreza, la deuda externa y la degradación ambiental. podemos desconocer que la crisis ha revelado deficiencias y puntos vulnerables. Los problemas son demasiado graves y sus consecuencias demasiado importantes, para conformamos con las respuestas del pasado o con las modas e ideologías del momento. La idea de que el desarrollo exige un esfuerzo total - un programa económico y social equilibrado - no es revolucionaria, pero la verdad es que no ha sido este el enfoque que estamos adoptando actualmente en la comunidad internacional" (ibid.).

En la actualidad, a raíz de la crisis, advirtió Wolfensohn, "necesitamos un segundo esquema, que se ocupe de la conservación del medio ambiente, la condición de la mujer, el desarrollo rural, las poblaciones indígenas, el progreso en materia de infraestructura y así sucesivamente... Además, debemos garantizar que se fomente y enriquezca la cultura de cada país, de modo que el desarrollo se construya sobre fundamentos firmes basados en la historia de cada uno de ellos. Debemos recordar en todo momento que son los países y su gente quienes tienen que decidir cuáles son sus prioridades. Debemos recordar en todo momento que no podemos ni debemos imponer el desarrollo por decreto desde arriba o desde el exterior" (ibíd.). Aunque se trate de frases dispersas, el valor del discurso es el reconocimiento de las debilidades y errores de las políticas recomendadas o impuestas desde estas instituciones internacionales. El verdadero desarrollo humano va más allá de los simples parámetros del crecimiento económico.

Desde 1970, en Davos, se reúne la elite del capitalismo. En 1999, se congregaron más de mil líderes de empresas, unos 300 dirigentes políticos, incluidos 40 jefes de gobiemo, y alrededor de 300 expertos en cuestiones económicas. La agenda del foro económico era "La globalidad responsable: la gestión del impacto de la globalización". Los documentos previos presagiaban un debate tenso. "La globalización debe adquirir un compromiso social, que no tenga como contrapartida la miseria y la exclusión de millones de seres humanos en el planeta". Los organizadores del evento lo introdujeron con tonos críticos: "Esta crisis es el resultado de una globalización que ha sido conducida de manera irresponsable. Los problemas creados por la mundialización han desembocado en una crisis sistémica. $O$ se diseñan nuevas medidas para hacer frente a la crisis o estamos condenados a entrar en un período de caos endémico y sistemático" (C. Swadja). El principal animador de la reunión, Klaus Achwad, "sostiene la necesidad de crear mecanismos globales e institucionales para lograr que la globalización se traduzca en fuente de bienestar para millones de personas que han sido condenadas a la miseria y al desempleo".

George Soros había dicho que "el Fondo Monetario Internacional no era parte de la solución; era parte del problema", con lo cual daba a entender que su gestión no ha sido la adecuada. Jeffrey Sachs, en El Salvador, dijo que esa institución "es una institución frustrante, pues nunca admite cuando ha cometido un error. No importa lo que pase, ellos supuestamente están en lo correcto y todos 
los demás se equivocan. Este tipo de arrogancia no es permisible para una institución internacional". Un último comentario adelantó lo que sucedería en la cumbre de Seattle, "La gestión de los desafíos económicos internacionales no puede seguir siendo monopolio exclusivo de las grandes potencias, a cuyas reuniones asisten los representantes de las naciones emergentes como 'invitados de piedra"'. Una vez iniciada la reunión, el Fondo Monetario Internacional se resistió a ser sentado en el banquillo de los acusados. Los comentarios previos no generan un proceso de autocrítica, con propósito de enmienda. Se admite que los efectos de la globalización son cada vez más perturbadores en casi todo el mundo, pero aquélla no puede ser controlada "sin quebrar el mercado, sin resucitar la excesiva intervención gubernamental y sin espantar a los innovadores que crean la tecnología y a los inversores que ponen el dinero". La globalización es imparable.

M. Castells recoge dos conclusiones sorpresivas. "Así, en último término, parece que hay que instalarse en la volatilidad financiera y en la inestabilidad económica y aprender a vivir en un mundo incierto, pero creativo y con potencial de ganancia". Es decir, que el potencial de ganancia justifica el resto de extorsiones mundiales. El capitalismo se define, pero no se corrige. Incluso la profecía del rebalse se estaría "humanizando". "De modo que el lado oscuro de la globalización se sitúa, sobre todo, en el drama humano que para cientos de millones de seres humanos representa - y esa responsabilidad se transfiere a las instituciones internacionales humanitarias, a las religiones y a la filantropía - un tema recurrente entre algunas de las más destacadas figuras empresariales". Esta es

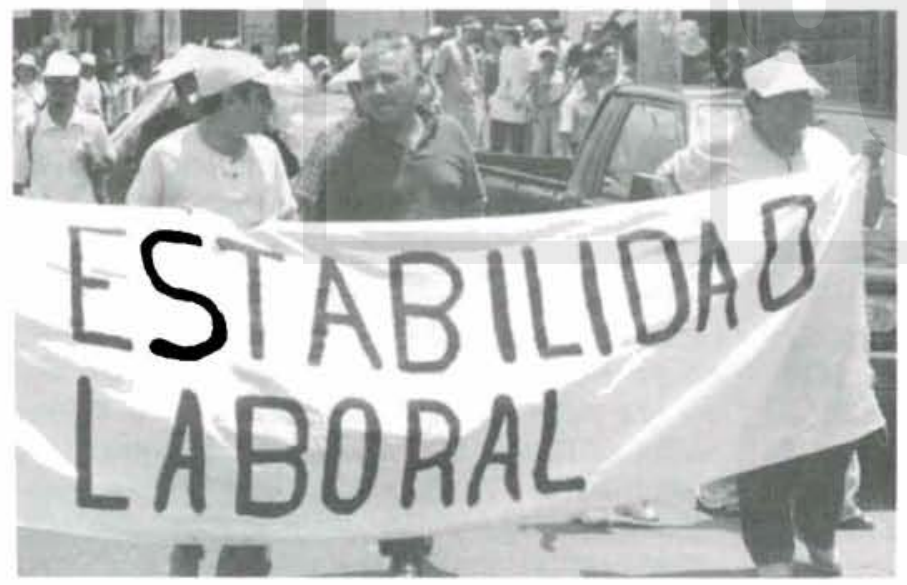

la solidaridad de los líderes del mercado. También se anuncia un rebalse, en estado de hibernación, "Por otro lado se espera que la promesa tecnológica, con tecnologías cada vez más potentes y baratas, que se difundirán entre toda la población, contribuya decisivamente a resolver los problemas". No dejan de ser irónicas estas promesas, cuando los creadores de cualquier tecnología defienden a capa y espada sus derechos de propiedad intelectual y son reacios al derrame de sus tecnologías.

Para Jorge G. Castañeda, "la sorpresa este año en el foro económico mundial estribó justamente en la desaparición del optimismo beato de la ciega exaltación del modelo, de la pureza impoluta e imprescindible del mercado. Al contrario, comprobamos algo ya presentido por muchos: nos hallamos de nuevo en el posneoliberalismo, transición que se detecta en tres tendencias, una de ellas clara y contundente y dos sujetas a mayores reservas y matices". La primera tendencia es "un consenso sobre la necesidad de controlar los flujos de capital de corto plazo", cuyas modalidades fueron discutidas en el foro. La segunda es la trilogía muy difícil de integrar de democracia, gobemabilidad y desigualdad. "Cunde la noción de que la creciente desigualdad en las sociedades modernas, no siempre comprensibles y asequibles, carcome y socava las formas de gobernabilidad también modernas. Como se ve la historia no ha muerto; el mundo no se detuvo con el último gran trastocamiento político ideológico, a saber la desaparición del socialismo", dice J. G. Castan̄eda (ibid., pp. 146-151).

En Seattle estalló "el malestar de la globalización" y la tesis de J. Stiglitz hizo historia, "la teoría del libre comercio es un fraude intelectual". Unos 50 mil manifestantes invadieron las calles de la ciudad. "La OMC es la Babilonia del segundo milenio, una especie de siniestra organización de rostro anónimo, convertida en el motor de una globalización que solo favorece a las grandes multinacionales". Los manifestantes se tomaron la calle "para dar la palabra a aquellos que jamás la han tenido y para que la Organización mundial del Comercio escuche la voz de los ciudadanos. La ley de las multinacionales no es la democracia. Se trata de que los pequeños países se hagan escuchar". De acuerdo con la tradición de otras cumbres, los puntos y el orden 
de la agenda fueron establecidos por las naciones industrializadas, mientras que los delegados de los países emergentes y en desarrollo asistieron como "invitados de piedra". Ahí surgió el debate de las ayudas a los agricultores europeos por $\mathbf{4 0 . 5}$ miles de millones de euros; similares a las de los agricultores norteamericanos por 22 mil millones de dólares.

Los delegados de los países pobres y emergentes echaron mano de la única respuesta que les estaba permitida. La norma de la Organización Mundial del Comercio establece que el acuerdo final necesita el voto unánime de los 135 representantes de los países miembros. En Seattle triunfó el desacuerdo de los emergentes y de los países en desarrollo, los cuales se negaron a firmar unos acuerdos finales que no les habían consultado, tampoco atendieron sus observaciones en su redacción final. La voz de los sin voz fue su desacuerdo, interpretado como una victoria. Los países africanos denunciaron acremente su marginación del proceso de negociación. Tuvieron la sensación de
Toda sociedad necesita tener valores compartidos. Los valores del mercado no sirven para este propósito, porque solo reflejan lo que un participante está dispuesto a pagar a otro, en un intercambio libre. Los mercados reducen todo, incluidos los seres humanos y la naturaleza, a mercancía. en la globalización. Sus críticos acusan a los países occidentales de hipócritas y con razón: forzaron a los países pobres a eliminar las barreras comerciales, pero ellos mantuvieron las suyas y les impidieron exportar productos agrícolas, privándolos de una renta indispensable, vía exportaciones. Estados Unidos fue, por supuesto, uno de los grandes culpables. En este entonces, Stiglitz era presidente del Consejo de Asesores Económicos del gobierno estadounidense, "batallé duramente contra esta hipocresía, que no solo daña a las naciones en desarrollo, sino que cuesta a los norteamericanos, como consumidores por los altos precios y como contribuyentes por los costosos subsidios que deben financiar, miles de millones de dólares. Con demasiada asiduidad mis esfuerzos fueron vanos $y$ prevalecieron los intereses particulares comerciales y financieros - cuando me fui al Banco Mundial aprecié con toda claridad las consecuencias para los países en desarrollo-" (ibíd., p. 31).

¿Qué nombre se puede dar a esta historia del que norteamericanos y europeos jugaron con la política del palo y la zanahoria, respecto a ellos. Cuando las discusiones, a puerta cerrada, se eternizaban y no se filtraba la información, los delegados de los países pobres, sin ánimo ni ilusión, aguardaron con paciencia en los pasillos. "No sabemos qué decisiones se van a tomar $y$, una vez más, se nos pedirá suscribir un texto que ni tendremos tiempo para leer". Seattle fue, al mismo tiempo, un fracaso y una victoria (ibíd., pp. 151-156).

Dos años más tarde, Stiglitz resumió la historia del comercio internacional, en una carta dirigida al G-7, reunido en Génova, "El sistema de comercio global está con problemas. Se predica el libre comercio como el evangelio en todas partes, pero parece que los países no hacen caso de su propio mensaje; sus mercados permanecen cerrados a muchos de los productos de los países en desarrollo, subsidian a sus agricultores en forma masiva, lo que hace imposible que los países en desarrollo puedan competir. El mensaje del G-7 parece ser: hagan lo que decimos, no lo que hacemos" (ibíd., p. 220). libre comercio internacional? Stiglitz usa muchas veces la palabra "hipocresía". Quienes se oponen, con razón, a la ratificación del ALCA, hablan de "neocolonialismo". En Davos (2001), Vandana Siva, directora de la Fundación para la Ciencia y la Ecología, afirmó que el proceso de globalización, en especial las barreras que los países ricos levantan a los productos agrícolas de los más pobres constituyen "un genocidio en una escala que la humanidad nunca ha conocido". India, dijo Vandana, está levantando las últimas restricciones a las importaciones, desde el 1 de abril de 2001, para cumplir con las normas de la Organización Mundial del Comercio, pese a que los países industrializados no levantarán las que pesan sobre productos textiles hasta el año 2005. "Estamos pagando un alto precio en términos de democracia. Porque con su globalización consiguen como respuesta la violencia, y entonces necesitan estados policíacos para defender este trato injusto" (ibíd., p. 213).

En Seattle estallan las divergencias, existentes en casi todas las cumbres mundiales, en torno al 
libre comercio. En Doha, la Unión Europea y Estados Unidos firmaron, sin ánimo de cumplir, un compromiso de "reducciones de todas las formas de subvenciones a las exportaciones, con miras a su progresiva reducción"; a lo cual agregaron que "reducción no significa eliminación". En 2003, en Cancún se quebró la "OMC del Desarrollo", no solo por el incumplimiento del pacto de Doha, sino porque los representantes de Estados Unidos y la Unión Europea intentaron discutir primero "los temas de Singapur" (inversiones, derechos de propiedad intelectual, servicios públicos y libre competencia). La hibernación de la Organización Mundial del Comercio permitió a los delegados estadounidenses sustituir los contratos multilaterales por tratados bilaterales. Pero los poderes económicos desiguales generan relaciones comerciales desiguales. $\mathrm{La}$ asimetría sigue vigente.

En la Xl Conferencia de Naciones Unidas sobre comercio y desarrollo, en Sao Paulo (2004), Brasil organizó el Grupo de los Veinte (G-20) para oponerse frontalmente a las subvenciones agrícolas de los países ricos. Annan dijo: "Es necesario hoy día, sobre todo, que se cumplan las negociaciones de Doha. Cada vez es más evidente que esto no se logrará si los países en desarrollo no tienen un acceso libre a los mercados de los países industrializados y las subvenciones agrícolas y otras, que deterioran el juego de los mercados mundiales, son eliminadas o, al menos, fuertemente reducidas. Esto sería un considerable progreso no solo en el plano de la coherencia, sino también del desarrollo y de la justicia". En una reunión entre representantes de Estados Unidos, Europa, India, Australia y Brasil, se intentó, en vano, desbloquear las tensiones agrícolas. Lula da Silva aprovechó la reunión para reforzar una cooperación entre los países del sur y propuso "suprimir sus barreras recíprocas sin extender dichas supresiones a los países desarrollados. Nosotros podríamos entonces reforzar la construcción de una nueva geografía comercial del mundo". En la reunión, 44 países firmaron este acuerdo y Brasil espera que otros 40 se sumen (Le Monde, 15 de junio de 2004). Este breve interludio muestra que los países ricos quitan con una mano mucho más de lo que dicen ayudar con la otra.

\section{Nuevo comienzo y mal final}

En el foro económico de Davos (2000) soplaron aires nuevos. Los organizadores del foro hablaron de un nuevo comienzo: "la nueva economía", el comercio electrónico y, más en concreto, de las transacciones vía electrónica, de empresa a empresa, con lo cual se eliminan las intermediaciones inútiles. Esta modalidad sería el motor del crecimiento y del cambio de cultura económica y financiera del mundo desarrollado. "No se esperan nubarrones en el horizonte; la economía mundial crecerá 4.5 por ciento en el año 2000; la crisis financiera quedó atrás. El euro se estaba consolidando y sobre todo la 'nueva economía' norteamericana estaba cumpliendo los 107 meses de crecimiento sostenido más largo de su historia. La nueva economía asegura que las futuras recesiones tendrán un efecto mucho menor y menos grave sobre la actividad económica, los beneficios empresariales y la cotización de las acciones". Los estadounidenses llegaron a Davos con los aires triunfales de César: "llegar, ver y vencer"; mientras que los europeos escucharon, como niños de escuela, los éxitos del "tótem del Internet".

Dos personas, sin embargo, encendieron la señal de alarma. El secretario del Tesoro, Larry Summers, "mostró su preocupación por el bajo ahorro de los hogares norteamericanos, algo que los expertos aquí reunidos llaman elevado endeudamiento, y que en el caso de ralentización económica colocaría en dificultades a muchas familias". Por su parte, Stanley Fischer, del Fondo Monetario Internacional, "aseguró estar inquieto por la desbocada marcha de la economía norteamericana, que podría verse abocada a una caída drástica en el caso de que los actuales ritmos de crecimiento no puedan ser controlados" (ibíd., pp. 166-167). En diciembre del mismo año 2000, Alan Greespan, presidente de la Reserva Federal, dijo: "Nuestra tasa de crecimiento probablemente es cercana a cero". El epicentro de la sacudida económica se situó en la bolsa de valores. "Entonces (Davos, 2000) el optimismo fue desbordante y generalizado, y los asistentes proclamaron sin mucho recato que Internet, la fuente del crecimiento económico de los Estados Unidos y la exuberancia de las bolsas de valores abrían una nueva prosperidad mundial. Pero en menos de un año los mercados de valores han trotado alegremente cuesta abajo, especialmente los títulos asociados a la nueva economía; numerosas empresas de Internet han echado el cierre y Estados Unidos está viviendo un fuerte enfriamiento de su economía, que amenaza con arrastrar a la economía del resto del mundo".

Según el historiador Lester Thurow, "Las razones son muy simples. Hay dos formas en que las empresas pueden ganar dinero invirtiendo en in- 
fraestructura de comunicaciones. Los beneficios pueden proceder de los precios que se cargan a los usuarios finales. Pero la recompensa es a largo plazo, a no ser que el mercado de valores pueda elevar a corto plazo el valor de las acciones de las empresas que están haciendo inversiones en infraestructura, basándose en que aquellas que más invierten son las que tienen mayores posibilidades de ser ganadores a largo plazo en las guerras de la telecomunicación. Y la segunda es lo que estaba sucediendo hasta que se derrumbó el mercado de valores de alta tecnología. Aquellos que invirtieron en infraestructura de telecomunicaciones se encontraron con que el valor de sus acciones subía más que los costos de las inversiones. Hoy día, después de la caída, el mercado de valores está haciendo todo lo contrario. Aquellos que contrajeron grandes deudas para financiar la estructura de telecomunicaciones están siendo penados por esas enormes deudas. Lo que antes se premiaba ahora se penaliza, y el nivel correcto de inversión está muy por debajo de donde estaba". En consecuencia, la confianza de los consumidores ha bajado de forma estrepitosa, una vez que las bolsas de valores no producen el mismo "efecto riqueza" que en el pasado, y que intuyen que, también como en los años ochenta, si se quedan en paro no tendrán tantas facilidades como hasta ayer para reponerlo con otro puesto de trabajo similar" (ibíd., pp. 210-211).

Un pequeño alto en el camino fue la victoria electoral de G. W. Bush, cuando la economía estadounidense, víctima de una especulación interna y generalizada, entró en una seria ralentización. "Nuestra tasa de crecimiento probablemente es cercana a cero". Dato histórico muy importante. El 6 de noviembre de 2000 , el gobierno de Irak, el segundo productor mundial del oro negro, "traslada todos sus petrodólares a la zona euro". Paul Harris, de la Universidad de Columbia, y J. Stiglitz, Premio Nobel de Economía 2001, se preguntan qué pasaría si la OPEP se cambiara al euro. El déficit record de la cuenta corriente se vería afectado de forma seria, así como también el estatus de Estados Unidos como principal nación deudora (ibíd., p. 271). “¡Explosión económica!", agrega J. Stiglitz. La recesión estadounidense tiene un origen interno, que se remonta a nueve meses antes del 11 de septiembre. La agenda del foro económico de Davos de 2001 fue, por eso, "recuperar el crecimiento y corregir las desigualdades".
Hay otro detalle que comenzó a llamar la atención. El gobierno de Bush desvió su radar del escurridizo Osama Bin Laden, refugiado en las tupidas montañas de Afganistán, y lo enfiló sobre Saddam Hussein, quien se convirtió en la gran amenaza económica y no militar. Como no se puede declarar la guerra a un país por transferir sus activos a la zona euro, se hace necesario recurrir a las alucinaciones y a la mentira. Desde marzo de 2003, se sabía que la "guerra preventiva" contra Irak se asentaba en la alucinación y en la mentira (ibíd., pp. 264-273). Paul O'Neil, primer secretario del Tesoro de Bush, afirmó que "la caída del presidente de Irak, Saddan Hussein, era prioridad de la presidencia, enero de 2001, ocho meses antes de los atentados del 11 de septiembre". "La Casa Blanca anunciaba planes de despliegue de fuerzas de paz, tribunales de guerra y también de distribución de las riquezas petroleras. Un plan para Irak después de Saddan Hussein". Hoy día está probado que nunca existieron las armas de destrucción masiva con las cuales se quiso legitimar la invasión y la destrucción de Irak para obtener ventajas económicas con su reconstrucción (Realidad 2004, pp. 30-31). ¿Quién es, por lo tanto el "eje del mal"?

\section{La Declaración del milenio}

En la cumbre de Naciones Unidas de noviembre de 2000 , se recopiló el cúmulo de problemas de finales del siglo XX. La Declaración del milenio es un juicio severo del siglo XX y un compromiso (¿fallido?) del nuevo milenio. Kofi Annan aseguró que había que "reinventar" Naciones Unidas: más población y más desafíos. "La globalización es muy beneficiosa para algunos y es potencialmente beneficiosa para todos, pero solo si los estados trabajan conjuntamente para que estos beneficios lleguen a todos. En contraste, miles de millones quedarán abandonados a la pobreza y otros países emergentes están a la merced de súbitos cambios económicos... Afrontamos desafíos mundiales que nos obligan a trabajar juntos, y si esto es cierto en la esfera económica, lo es aún mucho más ante el desafío que presentan las matanzas yuerras". Los cinco miembros del Consejo de \$eguridad desoyeron las voces de Boutros Ghali, cuando solicitó una policía internacional para detener las matanzas étnicas en Bosnia-Herzegobina, Ruanda, Sierra Leona, Timor y Zaire; al mismo tiempo que una gran potencia, por decisión propia, había intervenido (y lo seguirá haciendo) en otros países. 
"El instinto de solidaridad humana, que impulsa a algunos estados a acudir en ayuda de los ciudadanos de otros estados y a presentar cargos contra sus antiguos dictadores es digno de alabanza. Pero cuando estas acciones las aplican uno o pocos estados, en nombre de su propia autoridad, traen consigo el riesgo de la anarquía mundial". Clara alusión a la "guerra humanitaria" de Serbia-Kosovo, que Estados Unidos y la OTAN iniciaron sin autorización del Consejo de Seguridad. Kofi Annan solicitó a los estados miembros ratificar los estatutos de la Corte Penal Internacional, "que juzgue a los gent cidas, que los tribunales nacionales no pueden ó no quieran juzgar. El mundo estará más seguro si sabe que Naciones Unidas puede intervenir cuando está.amenazado con una destrucción masiva". En este punto se siguen levantando dos grandes obstáculos a la paz y a la seguridad del mundo: la estructura del Consejo de Seguridad y la negativa de las grandes potencias a ratificar los estatutos de la Corte Penal Internacional.

En esta cumbre se quiso tratar el tema de la renovación del Consejo de Seguridad, muy poco representativo de la estructura demográfica y de la política mundial. Pero los cinco países "con poder de veto" (Estados Unidos, Rusia, China, Inglaterra y Francia) se opusieron a compartir el poder. Solo se permitió que otros diez países se agregasen, en forma rotativa. Esta concentración de poder decisorio, en especial el "monopolio" del veto (basta "un veto" para anular cualquier decisión), hace posible que se sigan cometiendo crímenes de guerra, genocidios y crímenes de lesa humanidad. En la $58^{\mathrm{a}}$ cumbre de Naciones Unidas, en septiembre de 2003, se plantearon las siguientes preguntas: ¿Para qué sirve Naciones Unidas si no logra que se respeten sus resoluciones? ¿Cuál es la representatividad del Consejo de Seguridad y cuáles los criterios que le permiten decidir el uso de la fuerza? ¿Hay que conservar el "derecho al veto"? ¿Habrá que pensar en trasladar la sede Naciones Unidas fuera de Nueva York? ¿Cuál es la responsabilidad de la comunidad internacional cuando un Estado no protege a sus ciudadanos? (Realidad, 2003, pp. 739-742). Solo 90 de los 191 países miembros ratificaron los estatutos de la Corte Penal Internacional; solo cinco de los quince miembros del actual Consejo de Seguridad los habían ratificado. Estados Unidos, Rusia y China, tres de los cinco estados con poder de veto, los han ratificado. ¿Cuál es la seguridad de los débiles y cuál la solidaridad con el dolor del mundo?
La Declaración del milenio comienza con los "valores y principios": "la libertad, la igualdad, la solidaridad, la tolerancia, el respeto de la naturaleza y la responsabilidad común". "La solidaridad. Los problemas mundiales deben abordarse de manera tal que los costos y las cargas se distribuyan con justicia, conforme a los principios fundamentales de la equidad y de la justicia social. Los que sufren, o los que menos se benefician, merecen la ayuda de los más beneficiados". A la luz de estos principios se desgranan ocho bloques de problemas mundiales, que solo podemos enumerar de forma parcial. "La paz, la seguridad y el desarme" invitan a los países miembros a cumplir con las decisiones de la Corte Internacional de Justicia y a suscribir y ratificar los estatutos de Roma de la Corte Penal Internacional. "El desarrollo y la erradicación de la pobreza" descienden a las repetidas promesas de reducir y cancelar las deudas bilaterales de los países más pobres y abrir los mercados a las exportaciones de los menos adelantados; un sistema comercial y financiero multilateral abierto, equitativo, basado en normas, previsible, no discriminatorio".

El Programa 21, firmado en la cumbre del Medio Ambiente de Río Janeiro (1992), ha quedado en vía muerta, mientras la degradación ecológica amenaza la salud y la vida de miles de millones de personas. Se ha pedido a los estados miembros ratificar el Protocolo de Kioto (1997), pero "el mayor contaminante" tampoco lo firmará, en la cumbre de Johanesburgo (2002). "Derechos humanos, democracia y buen gobiemo" siguen siendo palabras "mártires", igual que verdad, paz y solidaridad. Detalle importante es un acápite dedicado a "la atención a las necesidades especiales de África", la cual acusó a los países ricos de su pobreza. "África es un continente rico, pero los africanos somos pobres". Algunos mandatarios tuvieron a bien recordar que, en 1888 , las potencias europeas se repartieron un continente rico en recursos naturales. ¿No hay lugar para un derecho retroactivo? La Declaración del milenio es un puente entre un siglo XX, que no puede ser "el fin de la historia", y un nuevo milenio que no acierta a mejorarla (Entorno económico mundial, pp. 195-208).

\section{La globalización está en serios problemas}

Si el éxito de la globalización se mide por los enunciados y los puntos de agenda de los foros económicos de Davos, quiere decir que los "maestros del mundo" contemplan un horizonte cargado 
de nubarrones. En Davos 2000 hubo euforia por la "nueva economía", la cual entró en abierta recesión, a finales de ese año. La agenda del foro económico del siguiente año fue "recuperar el crecimiento y reducir las desigualdades". Algo no marcha bien cuando se reduce el crecimiento y crecen las desigualdades. El gobierno de Bush no asiste a Davos, en 2001; mientras que los expertos plantean si hay recesión mundial (ibid., pp. 198-205). El 11 de septiembre ocurrieron los ataques terroristas, moral y humanamente condenables: no se pueden sacrificar vidas humanas, en aras de una ideología política, económica o religiosa. Cuando Bush califica estos ataques como "la primera guerra del siglo XXI", introdujo un peligroso quiebre en la historia del nuevo milenio: el terrorismo pasa a ser el "problema número uno del mundo". En este contexto, la Organización Mundial del Comercio, en Doha (2001), no pasa de ser un pacto de buenos compromisos, sin ánimo de cumplirlos. Sin embargo, surgió una novedad. Los manifestantes pacíficos, cansados de ir de cumbre en cumbre mundial con sus protestas, se congregan en Porto Alegre para transformar las protestas en una propuesta alternativa: "otro mundo es posible". Desde entonces, Davos tiene un contrincante o un interlocutor en Porto Alegre.

El foro económico de Davos de 2002 tuvo lugar en Nueva York. Ante los restos humeantes de las torres gemelas. Su agenda fue la economía frágil, la inseguridad, "la globalización de la ira se ha ido acelerando ante el rápido crecimiento de las desigualdades sociales". La suerte económica pasó a segundo plano y Bush relanzó la guerra contra "el eje del mal", Irak, Irán y Corea del Norte. "La historia nos ha dado la oportunidad de defender la libertad y de combatir la tiranía y esto es lo que hará nuestro país. Tal vez algunos se cansarán. Otros, tal vez, se fatigarán ante nuestros esfuerzos por la libertad. No así yo ni mi gobierno ni nuestro país". No se quiso escuchar la reflexión de Gorbachov: "Las víctimas de los atentados del 11 de septiembre en Estados Unidos no habrán muerto en vano si el mundo aprovecha la ocasión para mirarse en el espejo y reflexionar sobre sí mismo y establecer un compromiso moral, sin caer en el pánico". El pánico desplazará al compromiso moral.

En Porto Alegre se escuchan otras reflexiones. Rigoberta Menchú, Premio Nobel de la Paz, dijo: "Después de los atentados los temas sociales han sido totalmente dejados a un lado como si el dolor

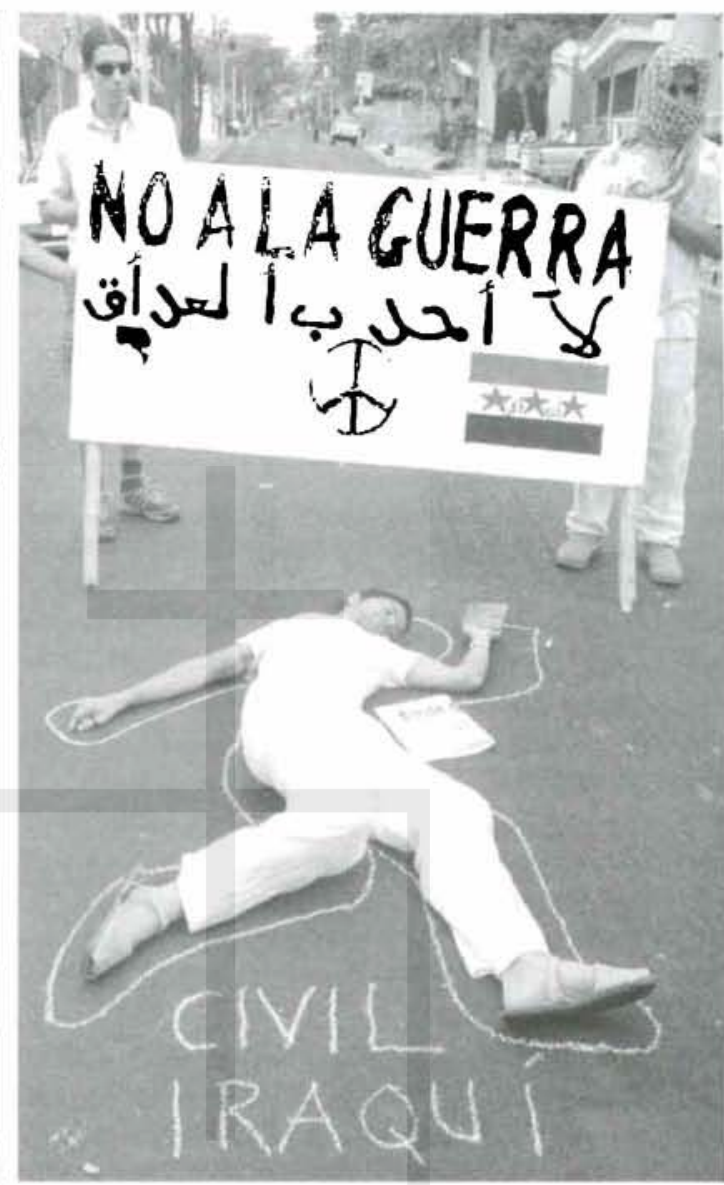

norteamericano hubiera opacado el dolor de todos los pueblos que sufren". El prefacio del programa de Porto Alegre declara que "Luego de los actos terroristas que nosotros condenamos, como condenamos todos los ataques contra civiles en cualquier parte del mundo, el gobiemo de los Estados Unidos y sus aliados han lanzado una operación militar masiva en nombre de la guerra contra el terrorismo. La guerra terrorista contra Afganistán tiende a extenderse sobre otros frentes. Es el comienzo de una guerra planetaria permanente para consolidar la dominación del gobiemo nosteamericano y sus aliados. La guerra revela la dtra cara del neoliberalismo brutal e inaceptable. En su esfuerzo por proteger los intereses de las grandes compañías el gobiemo norteamericano ha vuelto la espalda con arrogancia a las negociaciones sobre el 'efecto invernadero' (Kyoto), el tratado de misiles antibalísticos (ABM 1972), a la Convención sobre biodiversidad, a la Convención sobre el racismo, y 
ha demostrado, una vez más, que él resuelve unilateralmente los problemas mundiales".

Incluso dentro del foro económico de Nueva York, hubo reacciones críticas de los gobiernos de Rusia, China, Francia y de otros países europeos ante el discurso de Bush. El Ministro de Asuntos Exteriores de Francia, H. Vedrine, dijo, "Estamos amenazados hoy día por el nuevo simplismo de reducir todos los problemas del mundo a la simple lucha contra el terrorismo. Esto no es serio y no se puede aceptar esta idea. Si no estamos de acuerdo con las políticas norteamericanas debemos decirlo. Podemos decirlo y debemos decirlo". La numerosa delegación árabe criticó la posición unilateral del gobiemo de Bush. "Yasser Arafat es el único representante palestino", y Ariel Sharon no le había permitido llegar a este foro. Tal vez, la crítica más breve y más certera la hizo el arzobispo de Canterbury, G. Carei: "El capitalismo plantea hoy un interrogante. Es una palabra y es Enron".

En la economía estadounidense se abren grietas financieras, hechura de la tramposa especulación, encubierta por falsas auditorías y paraísos fiscales. La estrepitosa quiebra de Enron, la primera empresa de la rama de energía, que puede salpicar a La Casa Blanca, y Global Crossing, número uno en tecnología de fibra óptica, investigada por el $F B I$, hacen que el tema de los capitales especulativos forme parte de la agenda de Davos y Nueva York y también de Porto Alegre (ibíd., pp. 232-239). Muchos autores se preguntan si el celo belicoso de Bush contra el eje del mal externo no es un velo tupido sobre el eje del mal intemo, ya que varios estudios muestran que la serie de quiebras fraudulentas de tantas grandes compañías ha hecho más daño a la economía estadounidense que los ataques del 11 septiembre (ibid., pp. 257-258).

En estas circunstancias, la cumbre convocada por Naciones Unidas, en Monterrey, en 2002, dedicada al "financiamiento del desarrollo y el alivio de la pobreza", pasó sin pena ni gloria. La solidaridad brilló por su ausencia, pese a que el cálido discurso de J. Chirac se centró en "la mundialización de la solidaridad”. La luz se encendió y se apagó en el discurso de Bush: "Nosotros luchamos contra la pobreza con la esperanza de que ello sea una respuesta al terrorismo. Atacamos la pobreza, la indigencia, la falta de educación y a los ineficientes gobiemos que, con frecuencia, permiten que se den situaciones que los terroristas aprovechan para su causa... Desde hace décadas, el éxito de la ayuda al desarrollo se ha medido por el monto de los recursos gastados. Verter dinero sobre un estéril inmovilismo poco ayuda a los pobres e incluso puede retrasar las reformas y el progreso... Las naciones desarrolladas tienen el deber no solo de distribuir su riqueza, sino también de promover las fuentes que promueven la riqueza: la libertad económica, la libertad política, el Estado de derecho y los derechos humanos". En resumen, "la corrupción es un obstáculo para salir de la pobreza" y el resto son "declaraciones sin compromisos" (ibíd., pp. 239-248).

Tampoco tuvo mejor suerte la cumbre del desarrollo sostenible de Johannesburgo, justo una semana antes de celebrarse el primer aniversario del 11 septiembre. La "agenda 21 ", firmada en Río Janeiro, estaba estancada. La degradación ambiental se estaba convirtiendo en el creciente exterminio de los recursos naturales y en un lento, pero cruel "terrorismo" para la salud y la vida de millones de personas, en todo el mundo. Los documentos de la cumbre presentaban la gravedad del problema. Diez años antes, en Río Janeiro, había sonado la alarma: "se recalienta el clima, el agua limpia es un bien escaso, decenas de especies vivas se extinguen, la pobreza total abate a más de un millar de seres humanos... La causa principal de la degradación progresiva del medio ambiente mundial es el esquema de producción y de consumo inviable, sobre todo en los países industrializados, que es extremadamente preocupante por cuanto agrava la pobreza y los desequilibrios".

Los discursos de J. Chirac y G. Schroder trataban de catalizar la solidaridad mundial, de manera especial en los países más ricos y más contaminantes. En consecuencia, propusieron un compromiso concreto, que el 15 por ciento de la energía mundial fuera energía limpia y renovable. Ambos países se ofrecían a ayudar, técnica y financieramente, a los países pobres para aplicar estas nuevas fuentes de generación energética. La insolidaridad se impuso cuando el país más contaminante volvió a negarse a ratificar el protocolo de Kyoto ("es malo para la economía") y, además, junto con otros países petroleros, no apoyó la propuesta tranco alemana (ibíd., pp. 250-254). El problema es muy grave en El Salvador, porque "no somos extraterrestres" y sobran los documentos y las estadísticas que muestran la falta de conciencia y responsabilidad de los más poderosos para corregir la degradación ambiental. Basta leer, a modo de ejemplo, la publicación de la Fundación Salvadoreña 
para el Desarrollo Económico y Social, El desafío salvadoreño: de la paz al desarrollo sostenible (1997).

Por añadidura, las esperanzas de Qatar fueron ensombrecidas por los nuevos aranceles del gobiemo de Bush al acero y por el aumento de las subvenciones agrícolas. Luego de largas discusiones, Europa logró que la Organización Mundial del Comercio sancionara a Estados Unidos con 4 mil millones de dólares, por el uso ilegal de las "Corporaciones de Ventas al Exterior", que permite a grandes compañías exportar a través de estos paraísos fiscales, con lo cual reduce hasta un 30 por ciento la carga impositiva.

Así han funcionado grandes empresas industriales y la exportación de cereales y soya. "Es la perfecta ilustración de la hipocresía de la administración Bush sobre la liberalización del mercado", comentó Stiglitz (ibid., p. 255).

\section{6. "Construir la confianza"}

Este es el punto central de la agenda del foro económico de Davos de 2003. Building trust se había perdido y es lo último que se podía perder. Los organizadores del foro enviaron a los convocados el resultado de una encuesta pasada a $36 \mathrm{mil}$ personas de 47 países. Le Monde la resume de la manera siguiente: "Los dirigentes de las empresas están masivamente perdiendo la confianza del público. De todas las categorías, los dirigentes de las organizaciones no gubernamentales son los más creibles para la mayoría de ciudadanos ( 56 por ciento), seguidos por los líderes de Naciones Unidas y los jefes religiosos (41 y 42 por ciento). A los dirigentes de Estados Unidos se les concede la menor confianza". Y para que las cosas queden claras, "una mayoría de ciudadanos está en desacuerdo con la dirección en que evoluciona el mundo". ¿Cómo puede haber confianza cuando el mayor imperio defiende sus intereses económicos con tácticas de guerra? En Davos no se habló de economía, sino de una guerra que sigue siendo una amenaza para la economía y la humanidad.

Los discursos de Bush, el 6 y el 16 de marzo de 2003, están plagados de alucinaciones, falacias y mentiras. "Estoy convencido de que el pueblo norteamericano comprende que cuando se trata de nuestra seguridad, si debemos actuar, vamos a actuar, y no necesitamos realmente la aprobación de Naciones Unidas para hacerlo. No necesitamos el permiso de nadie. No dejaré al pueblo norteamericano a la merced de un dictador iraquí y de sus armas... Mi fe me sostiene, porque yo oro cada día. Pido que ella me guíe y me dé sabiduría y fuerza". Bush es prisionero de la peor alucinación que transforma una guerra económica en "guerra santa" (ibid., p. 267).

El discurso del 16 de marzo agrega a todo lo anterior la calumnia. "Desde hace más de diez años Estados Unidos y otros países han realizado pacientes y honrados esfuerzos para desarmar al régimen de Irak sin recurrir a la guerra. Nuestra buena fe no ha sido reconocida. El régimen iraquí ha utilizado la vía diplomática como una estrategia para ganar tiempo a su favor. Informes acumulados por éste y otros gobiemos no dejan duda alguna de que el régimen iraquí posee y esconde armas mortales jamás imaginadas. Este régimen ya ha utilizado armas de destrucción masiva contra los pueblos vecinos de Irak y contra el pueblo iraquí. Odia profundamente a Estados Unidos y a nuestros amigos y ha ayudado, entrenado y albergado a terroristas, incluidos agentes de Al Qaeda... Norteamérica ha procurado trabajar con Naciones Unidas para arreglar esta amenaza de manera pacífica. Nosotros creemos en la misión de las Naciones Unidas... El Consejo de Seguridad de Naciones Unidas incumplió sus responsabilidades y, por lo tanto, nosotros vamos a tomar las nuestras" (ibíd., pp. 269-270).

El resto de la historia es conocido, convierte al gobiemo de Estados Unidos en "el eje del mal" (Alain Touraine): de la mentira a la tortura de prisioneros de guerra, en Guantánamo y en las prisiones de Irak. Por desgracia, las tácticas de guerra se aplican a las relaciones comerciales. En la Organización Mundial del Comercio de Cancún se utilizaron tácticas de guerra similares. “¿Qué nos ofrecen ustedes para que nosotros les demos algo?", dijo Robert Zoellick. Se diría que el delegado de Estados Unidos estaba interesado en que el organismo quebrara para sustituir los "compromisos multilaterales" por relaciones comerciales bilatera- 
les, es decir, desiguales. El eurodiputado Samir Nair se pregunta si esto significa que el sur ha ganado el pulso. Por desgracia no. El fracaso de estas negociaciones debe ser lamentado por varias razones. En primer lugar, es un nuevo golpe al multilateralismo y a los esfuerzos por regular la globalización. Porque, en un mundo dominado por una única superpotencia, la elaboración de reglas comunes, vinculantes para todos, es una protección mucho más eficaz para los débiles que el cara a cara desigual con Estados Unidos. Éste no se ha equivocado. Robert Zoellick declaró tranquilamente, a la salida de la conferencia, "la estrategia comercial de Estados Unidos avanza en varios frentes. Tenemos acuerdos bilaterales con seis países. Negociaremos con los otros catorce" (ECA, 2003, pp. 1060-1070).

Luego del fracaso de Cancún, Horst Kholer, del Fondo Monetario Internacional comentó que "El bloqueo de las negociaciones comerciales internacionales en Cancún ciertamente no ayuda a reforzar la confianza a escala mundial. El comercio es un agente poderoso del crecimiento mundial y de la reducción de la pobreza. Los dirigentes de los grandes países industrializad tienen en sus manos la clave del éxito en las negociaciones, donde la agricultura es la clave de un decisivo progreso". James Wolfensohn, del Banco Mundial, defendió "un nuevo equilibrio entre países ricos y pobres. Lo sucedido en Cancún debe verse como una señal de alarma, porque los países en desarrollo - más de 3000 millones - consideran inaceptable una concepción de las negociaciones donde se espera de ellos que simplemente respondan a las propuestas de los países ricos. Dos tercios de los países en desarrollo dependen de la agricultura para su subsistencia y los países más ricos gastan más de $\mathbf{3 0 0}$ mil millones de dólares al año en subvenciones agrícolas y solo 56 mil millones de dólares, en ayuda pública al desarrollo". Nicholas Stern, economista jefe del mismo banco, calificó el sistema de subvenciones de los países ricos como "políticamente obsoleto, económicamente aberrante, destructivo del medio ambiente y éticamente indefendible. Ya es tiempo de hacer un alto" (Le Monde, 24 de septiembre de 2003).

\section{7. "Otro mundo es deseable"}

En los foros sociales de Porto Alegre se ha dicho que "otro mundo es posible". Sorpresivamente, en Davos de 2004 se dijo que "otro mundo es deseable". Parecería que "Davos se portoalegriza". Philipe Bourguignon y Thierry Malleret, directores del foro, afirman que el desafío mundial requiere integrar tres objetivos claves: cooperación, seguridad y prosperidad. En el mundo actual "no es posible la seguridad sin la prosperidad, ni la prosperidad sin la seguridad; ambos objetivos son inseparables. Igualmente, los problemas globales no pueden resolverse más que de una manera global, es decir, incluyendo a todos los actores claves, en la búsqueda de soluciones. De ahí la idea simple de la 'inseparabilidad' de las tres nociones; en esta correlación triangular, la ausencia de uno de los tres ingredientes compromete la idea misma de progreso. ¿Por qué? Es claro que vivimos un sentimiento de inseguridad y que, a ejemplo del 11 de septiembre, pueden repetirse graves incidentes de amplia repercusión. La mayoría de países desarrollados están pagando una 'sobretasa Bin Laden', que se traduce en miles de millones de euros, gastos militares, millones de horas perdidas en los aeropuertos a causa de los mayores controles de seguridad. Muchas industrias y servicios sienten el azote del terrorismo, al que se suman más de quince conflictos entre estados, docenas de guerras civiles y larvadas luchas interétnicas".

Lo bueno de estos autores es que introducen lo que Kofi Annan llamara "amenazas duras" y "ame-

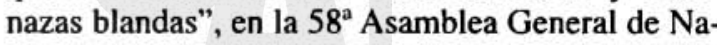
ciones Unidas. La seguridad debe entenderse en un sentido amplio, lo que Naciones Unidas llama la "seguridad humana". Los desafíos provocados por el hambre, la pobreza, toda clase de tráficos, la ausencia de un sistema de educación, de salud, o la falta de libertad son realmente gigantescos. Citando solo unos ejemplos: $800 \mathrm{mil}$ personas murieron el pasado año en conflictos bélicos; $22 \mathrm{mi}-$ llones murieron por falta de cuidados sanitarios y 800 millones siguen sufriendo de hambre. Más de 42 millones de personas padecen de sida y serán 
100 millones, en 2005. A todos interesa mejorar la "seguridad humana", porque es ahí donde se presenta la relación entre seguridad y prosperidad. Si hoy día 1800 millones viven con menos de un dólar al día, ¿es solo problema de ellos? No, es un problema de todos. Sin tomar en cuenta la obligación moral, es conveniente que los países ricos ayuden a los países pobres. ¿Por qué? Porque vivimos en una aldea global cada vez más interdependiente. La pobreza y la frustración de los demás se convierten en nuestro problema: la reducción del mercado a nuestros productos y servicios, el aumento de la emigración ilegal, la mayor contaminación ambiental, las enfermedades contagiosas, el fanatismo y el terrorismo.

Es necesario dar un sentido más amplio al concepto de prosperidad. No solo es capacidad de los países desarrollados para mantener un ritmo normal de crecimiento, sino también compartir, en forma equitativa, los frutos del crecimiento. Un mecanismo capaz de abolir la aterradora fosa que separa los países pobres de los países ricos. Esto no se realiza de forma espontánea porque, en contra de la teoría en boga, los países ricos se enriquecen más rápido que los pobres. En resumen, se parte de la economía y se cae, necesariamente, en la seguridad, la cual se mide por la capacidad para responder a una multitud de nuevos desafíos como el síndrome respiratorio, el terrorismo, las pandemias. Uno de los efectos de la globalización es que pone al descubierto estos problemas que parecían estar controlados. Internet, el celular y los aviones reducen el mundo y crean el sentimiento de cercanía.

¿Cómo resolver estos problemas globales, cómo mejorar al mismo tiempo la seguridad y la prosperidad? Con la cooperación. No hay otra solución, porque nadie, ningún grupo, ningún país, ninguna institución dispone de medios y de la necesaria legitimidad para llevar a término, por sí misma, esta tarea. Hoy día, la búsqueda de soluciones viables exige una forma de gobierno en red. En otras palabras, gracias a la cooperación entre la empresa (instituciones que crean el valor), la política (gobiemos y parlamentos) y la sociedad civil ampliada: organizaciones no gubernamentales, líderes sin- dicales, religiosos y académicos. Integrar la empresa y la sociedad civil es, ante todo, ampliar la representatividad y con ello la legitimidad, algo muy necesario, porque el mundo de la empresa y de la sociedad civil son verdaderos actores mundiales, a diferencia de los gobiernos, que tienen el poder de legislar, pero actúan localmente. Es una idea simple, pero muy eficaz para elaborar en común las soluciones a los problemas del mañana.

Al acabar de leer este documento surge una pregunta: $¿$ será posible integrar el "otro mundo posible" de Porto Alegre y Bombay con el "otro mundo deseable" de Davos? En enero de 2003, Lula da Silva habló en Porto Alegre y luego en Davos. Dicen que fue el discurso más aplaudido. En enero 2004, Joseph Stiglitz habló en Bombay y también en Davos. En Davos se dijo algo muy real y muy fuerte: "el eje del mal es la pobreza, el sida y la guerra", la guerra que hemos comentado. ¿Se estará abriendo "la estrecha ruta hacia la globalización de la solidaridad"? Sería lo deseable, pero todavía "son pocos los que quieren entrar por ella".

San Salvador, diciembre de 2004.

\section{Referencias bibliográficas}

Berzosa C. et alii, Estructura económica mundial. Madrid, 2001.

Cristianisme i Justitia. El neoliberalismo en cuestión. Santander, 1993.

De Sebastián Luis. Un mundo por hacer. Claves para comprender la globalizacien. Madrid, 2002.

Giddens Anthony. La tercera vía. La renovación de la socialdemocracia. Madrid, 1999.

Hinkelammert Frank J. "El socavamiento de los derechos humanos en la globalización actual: la crisis del poder de las burocracias privadas", Realidad, 2002, 87, pp. 328-329.

Ibisate, F. Javier. Entorno económico mundial. Apuntes guías. San Salvador, 2003.

Ibisate, F. Javier. "La sombra de Bombay se proyecta en Davos 2004", Realidad, 2004, 97, pp. 25-26.

Varii. "El neoliberalismo en América Latina". México, 1996. 